\title{
THE MIOTIC LIFE
}

These notes are written from the patient's point of view by a woman general practitioner with no specialized training in ophthalmology.

IN 1955, after some years in general practice, cupping of both optic discs was observed on routine examination by an ophthalmic medical practitioner who knew my family history. The diagnosis of glaucoma simplex was confirmed by the results of tests carried out at the Institute of Ophthalmology. I was then 47 years old and I had had no symptoms at all. I had always had a moderate myopia and had enjoyed satisfactory vision with glasses. My father, however, had had chronic glaucoma. The diagnosis in his case was not made until he was about 65 . He had small hypermetropic eyes. A trephine operation on one eye was unsuccessful and he eventually lost all sight in this eye, but he continued to read (he was a classical scholar) until the age of 78, and even at his death at the age of 89 retained a little vision. In my case when the diagnosis was established the routine treatment with miotics was started. Over the years the strength of the pilocarpine nitrate was increased from 1 to 4 per cent.; even so tension was only just within the tolerated limits, and at the same time there were gradually increasing field defects.

The diagnosis of chronic glaucoma brought with it the possibility of eventual loss of sight, partial or complete; for I understood that medical treatment was no cure, and that however regularly drops were instilled treatment might not be successful, and could not restore sight already lost. The threat of a handicapped old age was always present, but the use of miotics added to this a severe immediate disability, preventing the full use and enjoyment of eyes which, except for the increased tension, were optically sound.

Almost every facet of daily life was affected by the use of miotics. From the cosmetic point of view there was the expressionless eye with its pin-point pupil that never varied and was a constant reminder in the mirror of a dark future. Owing to lack of accommodation, make-up became difficult and lipstick and powder were not always properly applied. It was necessary to pay extra attention to lighting in bathroom and bedroom, and a torch was needed to search for objects in dark corners or under chairs. Apparent carelessness about dirty cups and dusty corners was due to miosis. A finger had to be used to judge the water level in filling a kettle, and many other tricks were acquired to make up for the limited light. Descending stairs presented difficulties even in a good light, and the groping uncertainty and lack of confidence produced the hesitant step of old age. These difficulties were all accentuated at night.

Colour vision was of course affected, especially for the darker shades. It became difficult to distinguish brown, green, blue, and purple, and it was embarrassing to be told by a shop assistant that a "nice violet suit" was really brown. Similarly, 
sewing on dark fabrics became impossible in artificial light. Night driving demanded increasing caution, though miotics do something to reduce the dazzle of headlights. This did not compensate for the increasing difficulty in picking out unlighted objects. In general practice visiting on winter afternoons became a great burden.

Other aspects of my work as a general practitioner were also affected. Although illumination in the surgery was good, fine work such as suturing, intravenous injections, removing foreign bodies from eyes, all presented problems. In the patients' homes, more often than not badly lighted, to the difficulties of clinical examination were added the hazards of dark stairs and unlighted hallways, garden paths with steps, and porches with illegible numbers.

Leisure activities were also affected by the loss of accommodation. Reading for any length of time became irksome. The enjoyment of games involving a moving ball, such as tennis, became impossible. It was also difficult to follow the flight of a golf ball; here perhaps loss of visual field was a contributory factor. Even spectator sports cease to be enjoyable under these conditions. Always a keen sight-seer, I found that old buildings had to be admired from the outside, and that visiting the interiors of Italian churches was very frustrating unless wall paintings and altar pieces were specially illuminated.

Although I had some knowledge of the symptoms and course of glaucoma, I was unable to distinguish the disabilities caused by the disease from those produced by the treatment. As time passed I became more aware of my limitations: Was difficulty with fine work due to increasing central field loss, or to lack of accommodation? Was difficulty in dark-adaptation due to glaucoma, or to miotics? So the present was clouded by doubts, there seemed to be only a short period of working life ahead, and that increasingly hindered by my disabilities. To retire early and enjoy reduced vision and a reduced pension, or to struggle on under a growing handicap with the same eventual outcome, this seemed to be the choice.

After 7 years of this discipline, successful operations on both eyes have released me from the bondage of the miotic life, and given me back my power of accommodation and a "pair of sparkling eyes", for the cosmetic result is important and rejuvenating.

To my delight and amazement, I find that my disabilities have gone, and that visual defects which I thought were due to disease were only the side-effects of treatment. I can walk confidently down unfamiliar stairs, no fumbling 70-year-old now, and see colours more brightly. I need no longer fear the dark winter afternoons. I can read for long periods, and do numberless things I thought I should never do again. My outlook is entirely changed. My working life is easier, I can again enjoy using my acquired skills and experience, and retirement has again receded to its proper distance.

With increasing facilities for the earlier diagnosis of glaucoma there will be many more patients like myself who will present themselves for treatment. Some of my difficulties and handicaps must be common to many patients treated by miotics; that is to say, they will be deprived of the full use of their eyesight at a time when they are at the height of their careers and should be enjoying the benefits of the skill and experience gained in their trade or profession. Although the end is good-the preservation of sight-are the means justified? To help the clinician in his choice of 
treatment it should be possible to measure the disability caused by miotics both subjectively and objectively. A carefully-designed questionnaire could be used to gauge the effect on the patient's life and work.

An objective assessment of disability could be made by comparing the results of tests of fields, colour vision, dark-adaptation, etc. under miotics, with the results of tests made after the patient had been allowed to dispense with his drops for a few days. (The only difficulty here would be to persuade the patient to return to regular use of his drops after his holiday. But he would at least have the satisfaction of knowing that his sight was being preserved, even if he was not allowed to use it!)

Is there a tendency to let concern over tension and visual field override consideration for the patient as a human being with a life to be led as fully as possible? Is it good medicine to establish and maintain a disability which must increase over the years as the ageing processes occur in the eye? How much sight must be given up at a time when it is most valuable, to secure a limited vision in the future, which some patients certainly will not live to enjoy?

This problem may eventually be solved by the development of drugs which reduce tension without miosis, but until these are generally used there will be many like myself who are condemned to the miotic life.

I hope these notes may throw some light on their problems. 